Research Article

\title{
Study on Properties of Cold-Sprayed Al-Zn Coating on S135 Drill Pipe Steel
}

\author{
Dongli Lv $\mathbb{D}^{1,2}$ Tao Zhang $\mathbb{D}^{1}{ }^{2}$ and Feiyang Gong ${ }^{1}$ \\ ${ }^{1}$ School of Material Science and Engineering, Southwest Petroleum University, Chengdu 610500, China \\ ${ }^{2}$ School of Oil and Natural Gas Engineering, Southwest Petroleum University, Chengdu 610500, China \\ Correspondence should be addressed to Dongli Lv; 1vl393@163.com
}

Received 20 November 2019; Revised 6 January 2020; Accepted 17 January 2020; Published 12 February 2020

Guest Editor: Ayodele Olofinjana

Copyright (c) 2020 Dongli Lv et al. This is an open access article distributed under the Creative Commons Attribution License, which permits unrestricted use, distribution, and reproduction in any medium, provided the original work is properly cited.

With the gradual depletion of shallow resources, the petroleum industry is developing toward ultradeep wells and high-speed drillings, and the problems of corrosion and erosion failure of drill pipe materials are becoming more and more serious. On the basis of not destroying the excellent mechanical properties of S135 drill pipe steel, three kinds of coatings, 20\% Al-80\% Zn, 30\% $\mathrm{Al}-70 \% \mathrm{Zn}$, and $40 \% \mathrm{Al}-60 \% \mathrm{Zn}$, are cold sprayed on S135 steel. The morphology of the coating is observed, and the bonding strength, porosity, hardness, and corrosion resistance of the coating are tested. Results show that the bonding mechanism between the powder particles and the substrate of the three coatings is mainly mechanical occlusion. From the substrate to the coating surface, the hardness value decreases gradually. With the increase of $\mathrm{Al}$ powder content, coating bonding strength increases, coating becomes more compact, and porosity decreases. Corrosion test results show that three coatings can protect the substrate. The density of corrosion products on the coating surface increased with the increase of the Al content. Corrosion potential of the three coatings is lower than that of the substrate, and the corrosion rate of the three coatings is lower than that of the substrate.

\section{Introduction}

In recent years, with the gradual depletion of shallow resources, the petroleum industry is developing toward ultradeep wells and high-speed drilling. S135 steel is widely used as drill pipe material because of its excellent mechanical properties [1]. As an important part of the drill string system, the drill pipe is often used as the circulation channel of drilling fluid. The drill pipe joint is the most important part of the drilling string. It plays the role of connecting, transforming, and transmitting torque. It must have high strength, plasticity, and other comprehensive mechanical properties. In the process of service, it is often affected by the corrosive medium, which makes the joint usually have corrosion behavior, so more than $80 \%$ of drill pipe accidents occur at joints. In recent years, the incidence of drill pipe failure accidents is very high, and the losses caused by the drill pipe failure also increased significantly $[2,3]$. It is necessary to find a surface treatment method to improve the surface properties of a material while retaining the excellent mechanical properties of S135 drill pipe steel, which is very necessary for improving the life of drill pipe and drilling efficiency [4].

The coating preparation technology has been paid close attention by domestic and foreign research institutions in recent years. The protective coating with excellent corrosion resistance and wear resistance can be prepared by thermal spraying or enamel technology. It has been widely used and developed because of its mature technology, convenient preparation, and flexible application, but there are inevitably many defects [5-9]. Cold spraying technology is a technology in which metal particles hit the substrate surface at high speed and form a dense coating on the substrate surface [10]. Compared with thermal spraying, cold spraying accelerates powder particles by compressed gas, and particles impact the surface of the substrate by their kinetic energy. After collision, plastic deformation occurs, which binds to the substrate and deposits a coating. Cold spraying can not only obtain nonoxidized metal deposits in the atmosphere, but also avoid the thermal impact on the substrate, which 
makes cold spraying technology have broad application prospects in corrosion protection and preparation of high conductivity coatings, repair of damaged metal components, and manufacture of metal additives.

Under the action of high-speed and high-pressure gas, the fully solidified high-speed particles collide with the substrate violently, and the particles deform plastically and deposit, forming a cold spray coating. Assadi et al. used the finite element method to simulate the stress field and temperature field distribution of particles bonded to the substrate. The results showed that there was microzone melting at the particle edge and proposed that metallurgical bonding might exist in the process of cold spraying $[11,12]$. Al coating can provide good cathodic protection for steel surface, and the performance of protective coating is better than that of thermal spraying [13]. In terms of electrochemical protection, $\mathrm{Zn}$ has a better effect than $\mathrm{Al}$. While in terms of electrochemical stability, Al has a better effect than $\mathrm{Zn}$. At the same time, by comparison with the two elements, it can be found that zinc-aluminum composite coating is a more excellent coating material combining the excellent cathodic protection of $\mathrm{Zn}$ and the excellent chemical stability of $\mathrm{Al}[14,15]$. Al-Zn composite coating has lower porosity and better corrosion resistance than pure aluminum and zinc coatings [16-18]. The composite coating with the substrate and the internal powder of the coating can be well combined, and the Al-Zn alloy coating prepared by cold spraying has higher wear resistance [19].

In this paper, three proportions of $\mathrm{Zn}-\mathrm{Al}$ coatings, $20 \%$ $\mathrm{Al}-80 \% \mathrm{Zn}, 30 \% \mathrm{Al}-70 \% \mathrm{Zn}$, and $40 \% \mathrm{Al}-60 \% \mathrm{Zn}$, were sprayed on the surface of S135 steel which was commonly used in oil drilling engineering. Microstructure, morphology, porosity, hardness, bonding strength, and corrosion resistance of three coatings were observed and studied.

\section{Experimental Process}

2.1. Experimental Materials. The substrate material used in the experiment is S135 steel plate, and its chemical composition is shown in Table 1 . The substrate thickness is $10 \mathrm{~mm}$.

Figure 1 shows the micromorphology of $\mathrm{Al}$ and $\mathrm{Zn}$ powders. The particles of $\mathrm{Zn}$ powders were spherical and ranging from 5 to $14 \mu \mathrm{m}$ in size. The particles of $\mathrm{Al}$ powders were not uniform, and most of them are strip or wormlike, ranging from 15 to $45 \mu \mathrm{m}$ in size. The purity of the two kinds of metal powder was more than $99.9 \%$.

2.2. Preparation of Spray Coating. In order to improve the mechanical occlusal effect between the coating and the metal substrate, acetone and alcohol were used for ultrasonic cleaning to remove stains and rust on the substrate surface before spraying. Sandblasting pretreatment with quartz sand was used to increase the roughness of the substrate surface, which was beneficial to the bonding between the coating material particles and the substrate. Metal powders of $\mathrm{Al}$ and $\mathrm{Zn}$ were mechanically mixed at the weight proportions of 20\% Al-80\% Zn, 30\% Al-70\% Zn, and 40\% Al-60\% Zn, respectively. Low pressure cold spraying equipment (DYMET-413) was used for spraying. Figure 2 shows the working principle of the cold spraying system. The gas is pressurized by a compression device and then heated through a heater to expand at supersonic speeds at the nozzle outlet. Metal powder particles are accelerated to supersonic velocity by high pressure heating gas at the front of the spray gun and then rushed to the surface of the substrate to bond with it. The working gas was $\mathrm{N}_{2}$, the spray gas pressure was $0.8 \mathrm{MPa}$, and the powder feeding rate was $0.556 \mathrm{~g} / \mathrm{s} \sim 1.389 \mathrm{~g} /$ s. Spraying temperature was $500^{\circ} \mathrm{C}$. The distance between the spray gun and the surface of the substrate was maintained at $15 \sim 30 \mathrm{~mm}$, and the lateral movement was at the speed of $20 \sim 30 \mathrm{~mm} / \mathrm{s}$. The thickness of coating was measured with a vernier caliper. The thickness of the coating was obtained by subtracting the thickness of the substrate before spraying from the thickness of the test piece after spraying. Five measuring points were selected on the spraying test piece to obtain the average thickness. The thickness of $20 \% \mathrm{Al}-80 \%$ $\mathrm{Zn}$ coating was $327 \mu \mathrm{m}, 30 \% \mathrm{Al}-70 \% \mathrm{Zn}$ coating was $346 \mu \mathrm{m}$, and $40 \% \mathrm{Al}-60 \% \mathrm{Zn}$ coating was $367 \mu \mathrm{m}$.

\section{Results and Discussions}

3.1. Microstructure Observation of Coating. Figure 3 shows the micromorphology of coatings with three powder ratios observed by scanning electron microscopy. It can be seen from the figures that the surface of the three kinds of coatings is uneven, and there are some round particles with a diameter of about $5 \mu \mathrm{m}$. There is a critical deposition velocity determined by material properties in cold spraying. Only the powder beyond the critical velocity can be deposited on the substrate to form the coating $[20,21]$. Most of the powder particles have severe plastic deformation, while a few of the small particles have not been fully deposited due to their impact velocity not reaching the critical velocity, so there are a few particle gaps or holes on the coating surface. With the increase of the relative content of aluminum powder particles, the roughness of the coating decreases, porosity of the coating surface decreases gradually, and the coating becomes more compact. Because the particle size of aluminum metal powder is larger than that of zinc metal powder and irregular, the kinetic energy of aluminum powder particles impacting on the substrate is larger in the gas-solid twophase flow field during spraying process. After aluminum powder particles continuously impacting on the substrate, the crystal blocks are broken and refined, the deformation is obvious, and most of them are flat. Zinc powder particles are brittle at a certain temperature. It is easy to be broken into fine particles and deposited in the process of coating preparation, which makes the coating more compact and greatly reduces voids caused by overlapping particles, thus reducing the porosity and the roughness of the coating.

Figure 4 shows the microstructure photos of the three polished coating sections. It can be observed that the three coatings are even and flat, the micropores formed in the deposition of $\mathrm{Al}$ and $\mathrm{Zn}$ powders are less, and the combination is compact. In the coating, aluminum-zinc powder particles become soft due to continuous heating by heated 
TABle 1: Chemical composition of S135 steel (wt.\%).

\begin{tabular}{lccccccccrr}
\hline $\mathrm{C}$ & $\mathrm{Si}$ & $\mathrm{Mn}$ & $\mathrm{S}$ & $\mathrm{P}$ & $\mathrm{Ni}$ & $\mathrm{Cr}$ & $\mathrm{Mo}$ & $\mathrm{Ti}$ & $\mathrm{Cu}$ & $\mathrm{Fe}$ \\
\hline 0.28 & 0.25 & 0.64 & 0.004 & 0.008 & 0.29 & 0.98 & 0.42 & 0.009 & 0.02 & 96.876 \\
\hline
\end{tabular}

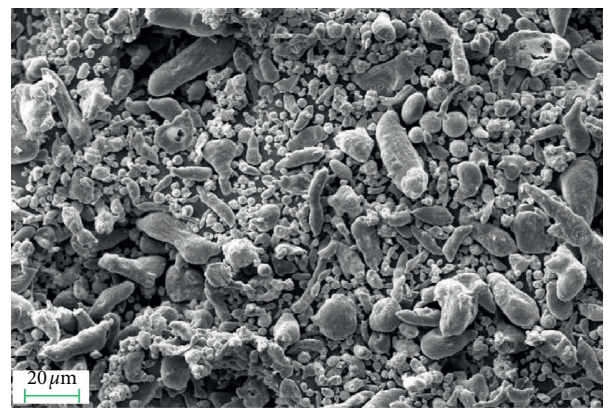

Figure 1: SEM image of mixed powder of $\mathrm{Al}$ and $\mathrm{Zn}(40 \% \mathrm{Al}-60 \% \mathrm{Zn})$.

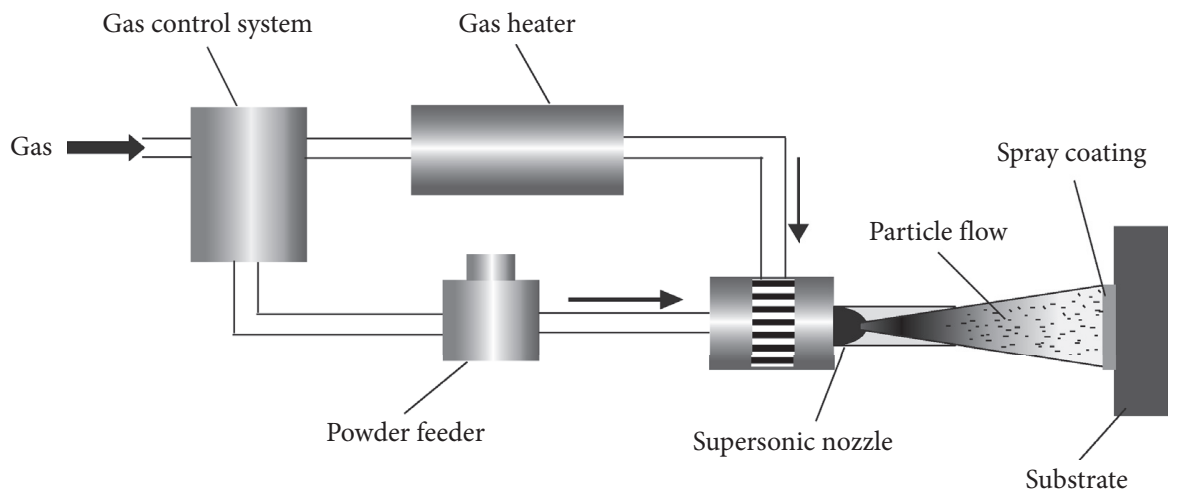

Figure 2: Principle diagram of cold spraying process.

gas and are continuously impacted by subsequent particles, resulting in obvious plastic deformation. The mutual squeezing between the particles causes the two powders to mechanically bond together, presenting a flat strip bonding form and piling up layer by layer to form a dense coating. With the increase of the content of aluminum powder, the plastic deformation degree of powder particles is increased, and the flat strip structure formed by the combination of the two powder particles is more compact.

Porosity directly affects the performance of coatings. When coatings are used for corrosion resistance, the value of porosity is a key index to measure the quality of coatings. When the porosity is high, the corrosion rate of the coating accelerates, and the corrosive medium can easily enter into the coating or intensifies the corrosion of the substrate interface, which leads to the decrease of the corrosion resistance of the coating. The porosity of coatings was calculated with the aid of image processing method [22]. By using M180-50120 metallographic examination software system, the porosity of the coating is evaluated automatically by "calculating the distribution and size of porosity." The gray value of the metallographic photograph is analyzed by the gray value method in the metallographic inspection software system to capture the position and size of the pores and determine the porosity of the coating. The porosity of the three coatings is shown in Figure 5. It can be seen from the figure that the porosity of the coating decreases gradually with the increase of aluminum powder content in the coating and the decrease of zinc powder content. When the metal powder particles impact S135 steel matrix during spraying, both of them have plastic deformation, which makes the surface of the matrix appear pits, and the coating powder is trapped in the pits to form mechanical bond. Within the coating, along the stacking direction of the coating, the plastic deformation of the powder particles decreases, the incomplete overlapping rate of the powder increases, the coating structure gradually becomes loose, and the pores gradually increase. With the increase of $\mathrm{Al}$ content in the powder, the large size of $\mathrm{Al}$ particles is easy to accelerate in the gas-solid two-phase flow field, the deposition efficiency of the whole coating increases, and the large kinetic energy is obtained to generate sufficient plastic deformation. In addition, the continuous impact of the powder particles makes the crystal block broken and refined, greatly reducing the incomplete overlap between the particles and reducing the porosity. The porosity of the three types of cold spraying coatings are all less than $1.6 \%$, of which the $40 \% \mathrm{Al}-$ $60 \% \mathrm{Zn}$ coating was only $0.62 \%$, indicating that the porosity 

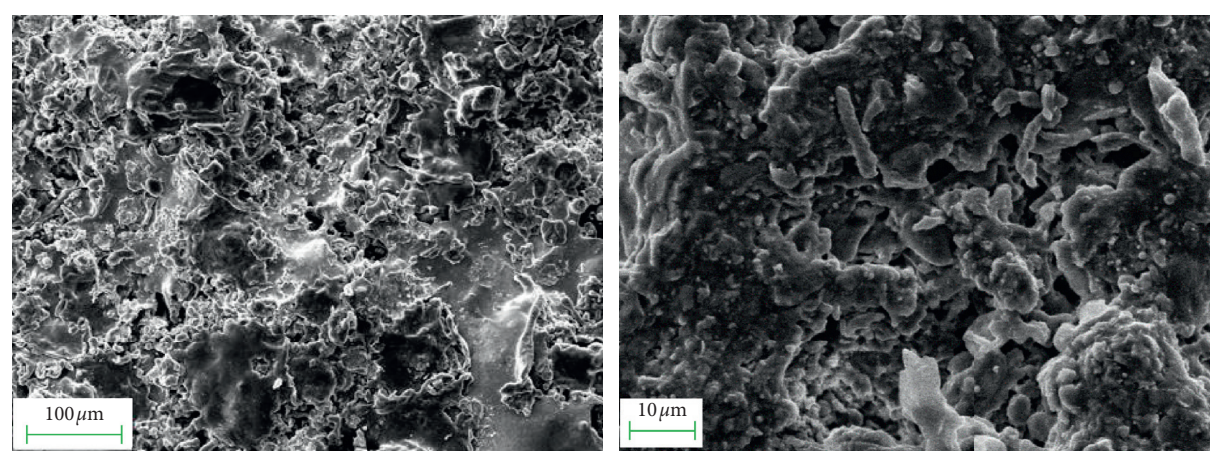

(a)
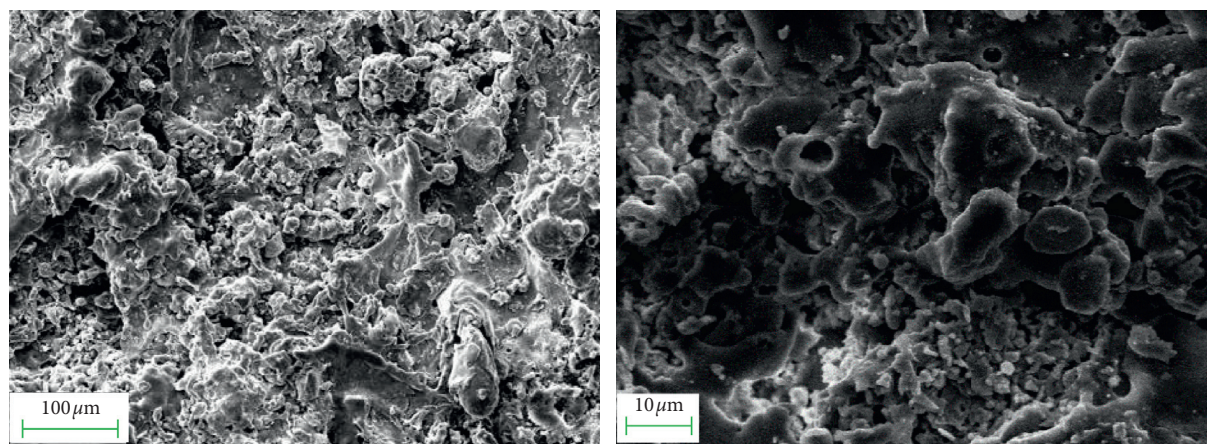

(b)
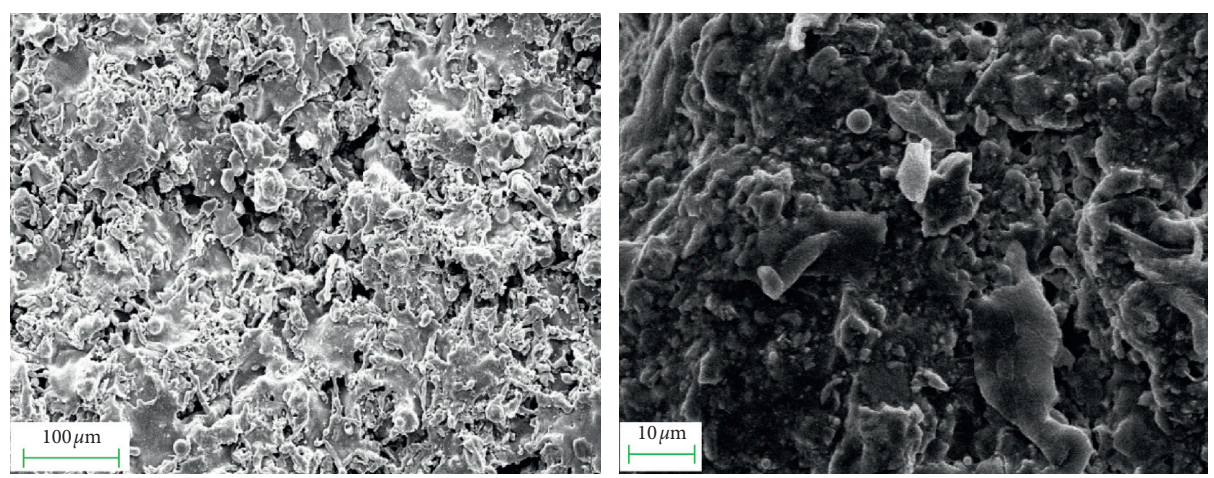

(c)

FiguRE 3: Surface micromorphology of different coatings: (a) $20 \% \mathrm{Al}-80 \% \mathrm{Zn}$, (b) $30 \% \mathrm{Al}-70 \% \mathrm{Zn}$, and (c) $40 \% \mathrm{Al}-60 \% \mathrm{Zn}$.

of the three types of cold spraying coatings produced in this experiment is lower than that of the thermal spraying coating in which porosity is usually $5 \%-15 \%$. $[23,24]$.

3.2. Hardness and Bonding Strength of Coatings. Coating hardness is a key index to evaluate the quality of coatings, and it can reflect the wear resistance of coatings. When the particle velocity reaches the critical velocity, severe plastic deformation will occur after the particle impacts the substrate and then the coating will be deposited. In addition, some particles whose velocity is less than critical velocity will produce shot peening strengthening effect on the deposited coatings, which will result in deformation hardening effect in the coatings.

Figure 6 is a schematic diagram of the hardness testing position. Five locations are taken from the substrate to the coating along the thickness direction for hardness testing. Five points in the horizontal direction are taken for hardness testing at each location, and then the average value is taken as the hardness value of the position. The hardness result is shown in Figure 7. According to the figure, the hardness values of the three coatings decrease gradually from the substrate to the surface of the coatings. Because of the high hardness of the substrate, the spray particles impact the substrate at high speed and form the initial coating. The initial coating is greatly affected by the matrix hardness, so the hardness is higher. At the same time, the impact of subsequent particles also strengthens the deposited coating and obviously improves the hardness of the coating. The closer the coating surface is, the less and less the impact of subsequent particles on the coating is, and the weaker the hardness strengthening effect is. As the hardness of the zinc powder particle is much higher than that of aluminum 


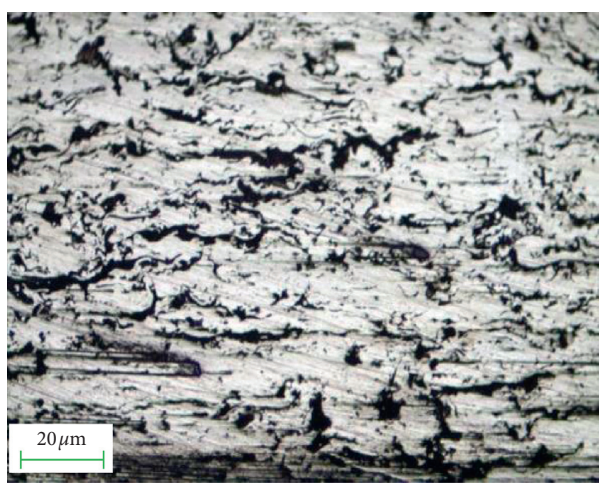

(a)

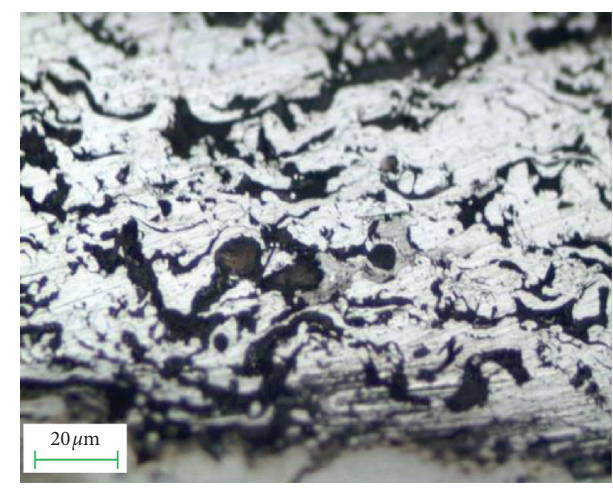

(b)

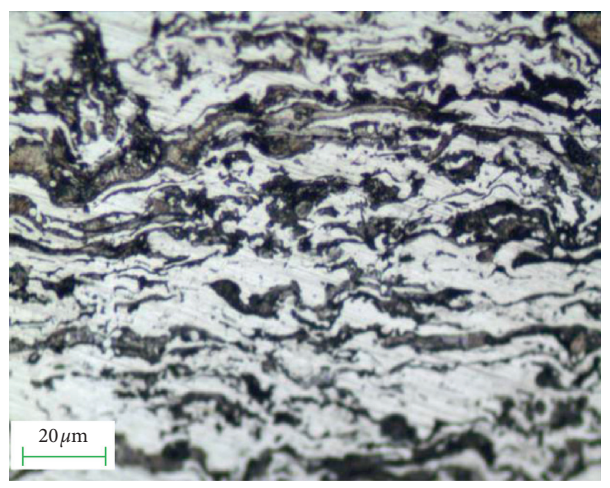

(c)

FIGURE 4: Metallographic photograph of the coating section: (a) 20\% Al-80\% Zn, (b) 30\% Al-70\% Zn, and (c) $40 \% \mathrm{Al}-60 \% \mathrm{Zn}$.

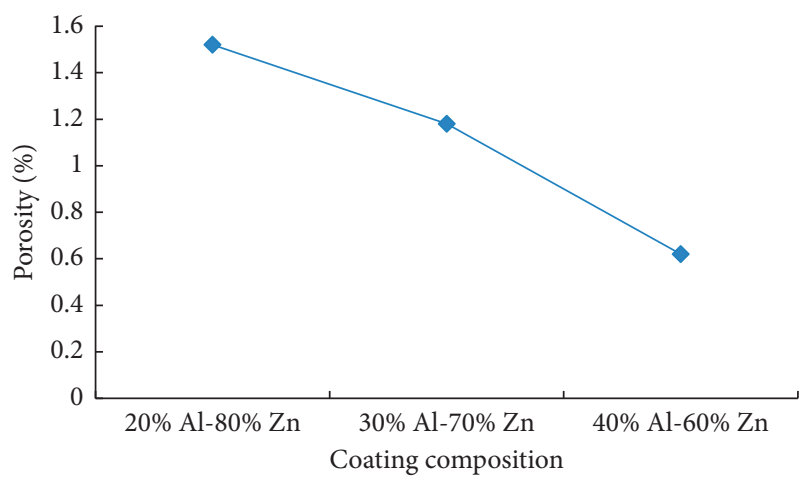

Figure 5: Porosity variation of the three coatings.

powder particle, the hardness of coating increases with the increase of the content of zinc powder particles. Because the drill pipe joint is more prone to corrosion failure, the surface hardness requirement of drill pipe joint is not as high as that of corrosion resistance. In this paper, although the hardness of the coating obtained by cold spraying Al-Zn coating is lower than that of the substrate, we can try to improve the hardness in the follow-up study, in order to obtain a coating with better comprehensive performance.

As another important performance index of coating, bonding strength can reflect the bonding between coating and substrate or the adhesion inside coating, directly reflect the mechanical properties of coating, and affect the service life of coating. On the multifunctional material surface

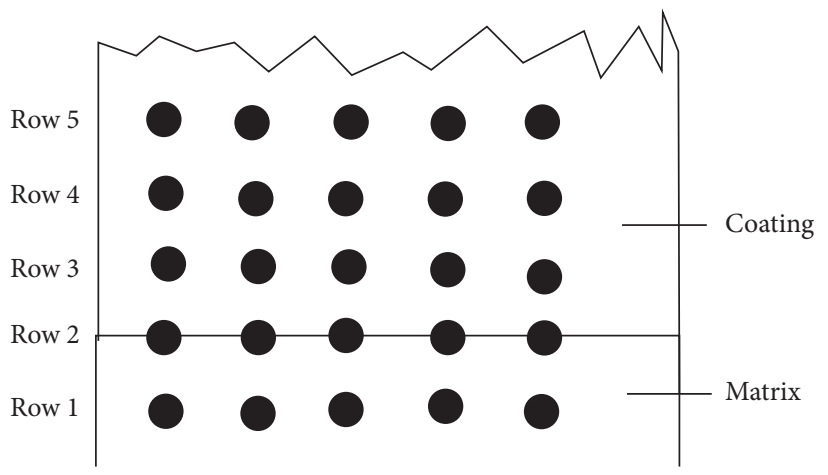

FIGURE 6: Schematic diagram of the hardness testing position.

performance testing machine, the scratch test was carried out on the coating surface with $120^{\circ}$ natural diamond indenter. Under the condition of the preloading load of $15 \mathrm{~N}$, loading speed of $100 \mathrm{~N} / \mathrm{min}$, and scratch length of $10 \mathrm{~mm}$, the acoustic signal of scratch interface is collected by the acoustic signal receiver. The bonding strength between coating and S135 steel substrate is reflected by the magnitude of loading force when the acoustic signal changes abruptly. The scratches produced by the indenter on the substrate are shown in Figure 8. The craters can be clearly observed in scratch photographs which prove that the coating has been scratched to the substrate when the sound signal suddenly changes. There is no large area of coating falling off on both sides of the scratch, showing good bonding performance 


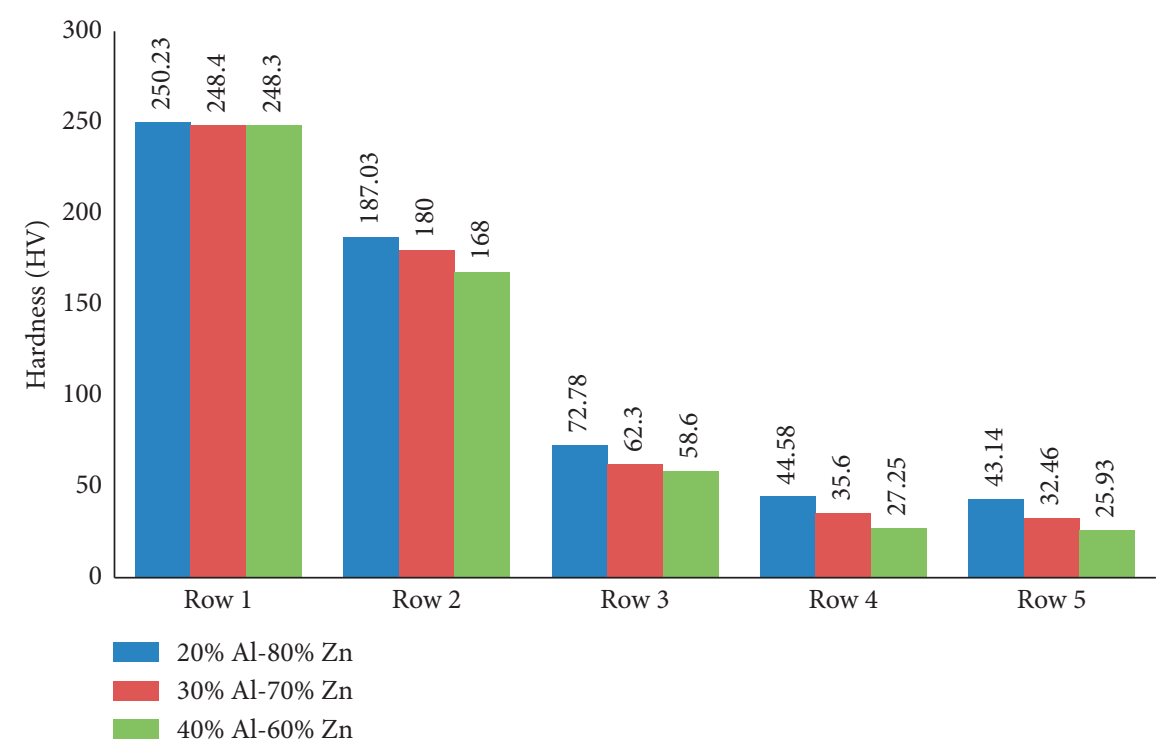

Figure 7: Hardness of the three coatings.

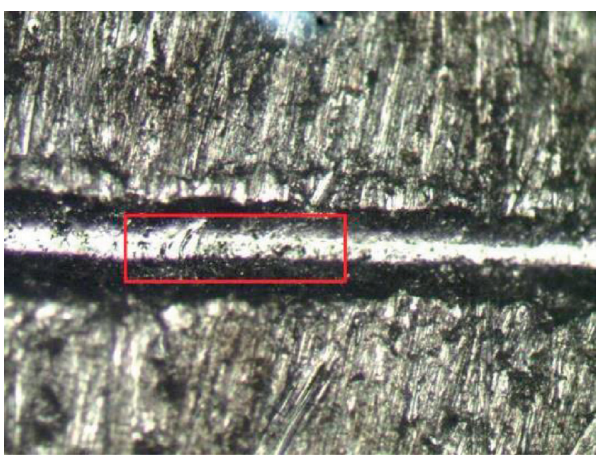

(a)

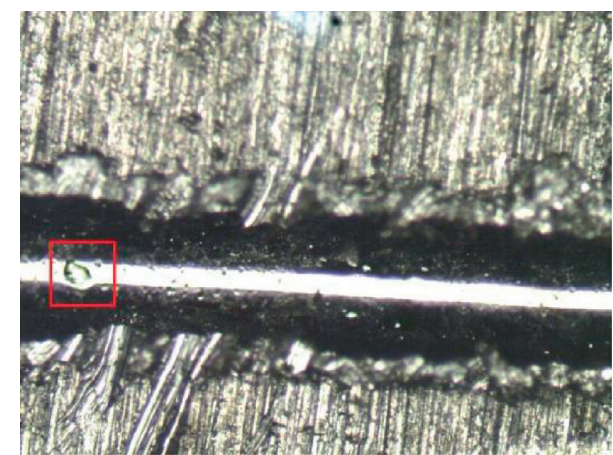

(b)

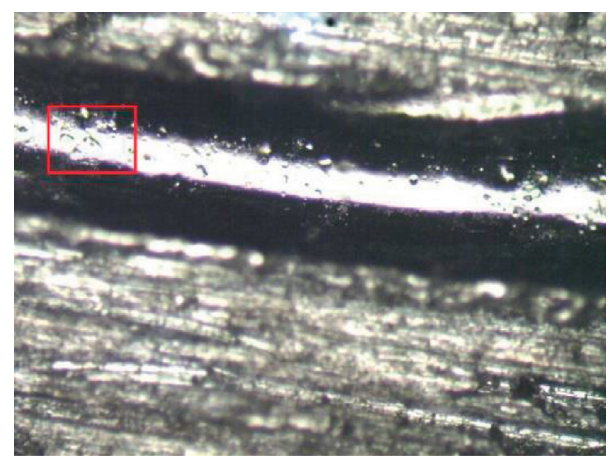

(c)

FIgURE 8: Scratch charts of three coatings: (a) $40 \% \mathrm{Al}-60 \% \mathrm{Zn}$, (b) $30 \% \mathrm{Al}-70 \% \mathrm{Zn}$, and (c) $20 \% \mathrm{Al}-80 \% \mathrm{Zn}$.

with the substrate. The critical loading forces between the coating and the substrate are measured as shown in Table 2. It can be seen from the table that different loading forces are required to penetrate the binding interface of the three coatings and the substrate. The bonding strength of the coating increases with the increase of the $\mathrm{Al}$ content. Due to the large particle size of $\mathrm{Al}$ metal powder, it is easy to be accelerated in the gas-solid two-phase flow field during spraying, and the kinetic energy obtained and the impact force generated when it collides with the matrix are large. At the same time, due to the large amount of plastic deformation caused by the irregular shape of $\mathrm{Al}$ particles, the bonding strength between powder particles and matrix is improved. The critical failure loads of the three coatings are not very large, which is mainly related to the hardness of the matrix material. Because, under the external load, the 
TABLe 2: Critical loading force of three coatings.

\begin{tabular}{lr}
\hline Powder proportion & Critical loading force (N) \\
\hline $20 \% \mathrm{Al}-80 \% \mathrm{Zn}$ & 41.73 \\
$30 \% \mathrm{Al}-70 \% \mathrm{Zn}$ & 44.53 \\
$40 \% \mathrm{Al}-60 \% \mathrm{Zn}$ & 48.95 \\
\hline
\end{tabular}

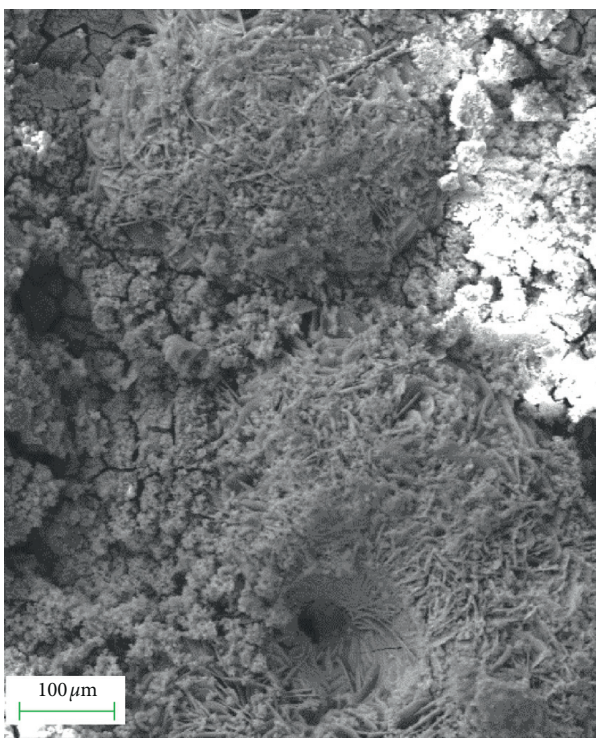

(a)

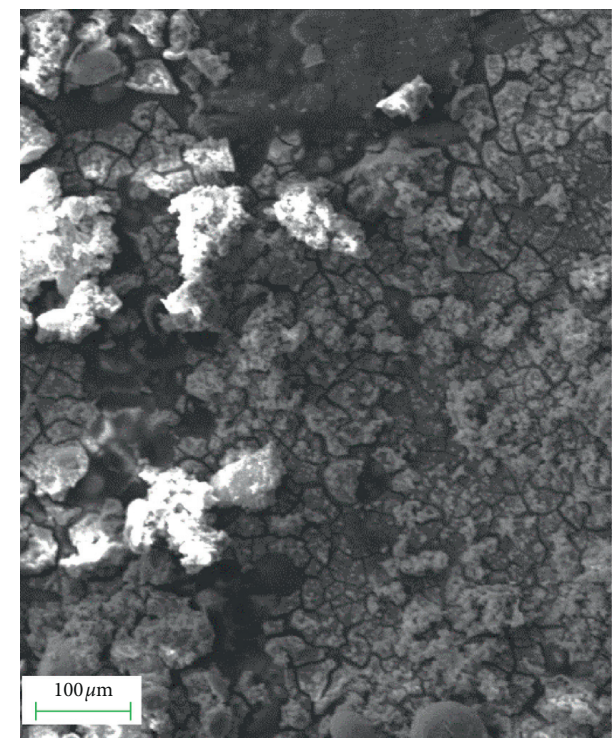

(b)

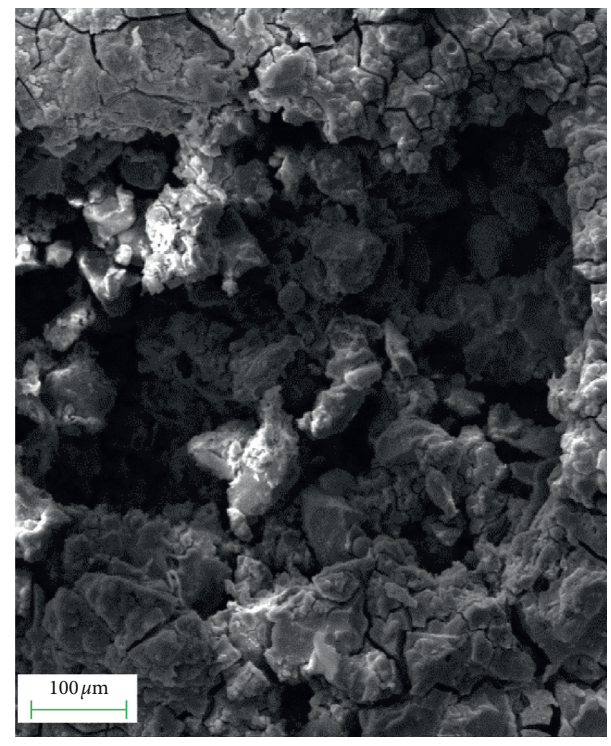

(c)

Figure 9: SEM diagram of surface morphology of coating after corrosion: (a) $40 \% \mathrm{Al}-60 \% \mathrm{Zn}$, (b) $30 \% \mathrm{Al}-70 \% \mathrm{Zn}$, and (c) $20 \% \mathrm{Al}-80 \% \mathrm{Zn}$.

deformation of the coating and the substrate must be in a state of collaborative deformation, so that the film has the best bonding performance.

3.3. Corrosion Behavior of Coatings. As a kind of anode coating, Al coating not only has the function of isolating corrosion medium and making it unable to react with the substrate but also is a kind of sacrificial anode material, which plays the role of cathodic protection. $\mathrm{Zn}$ coating is often used as sacrificial anode to protect steel. Al-Zn composite coating has both advantages. $10 \% \mathrm{NaCl}$ solution was chosen as corrosion solution in the immersion corrosion experiment. The morphology of coating was observed after 480 hours. By observing the corrosion surface morphology of the three coatings after immersion corrosion, it was found 


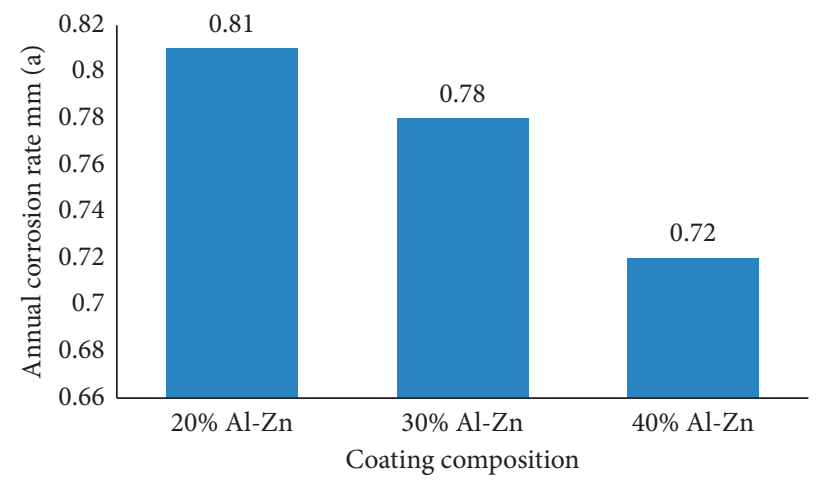

FIGURE 10: Corrosion rate of each coating.

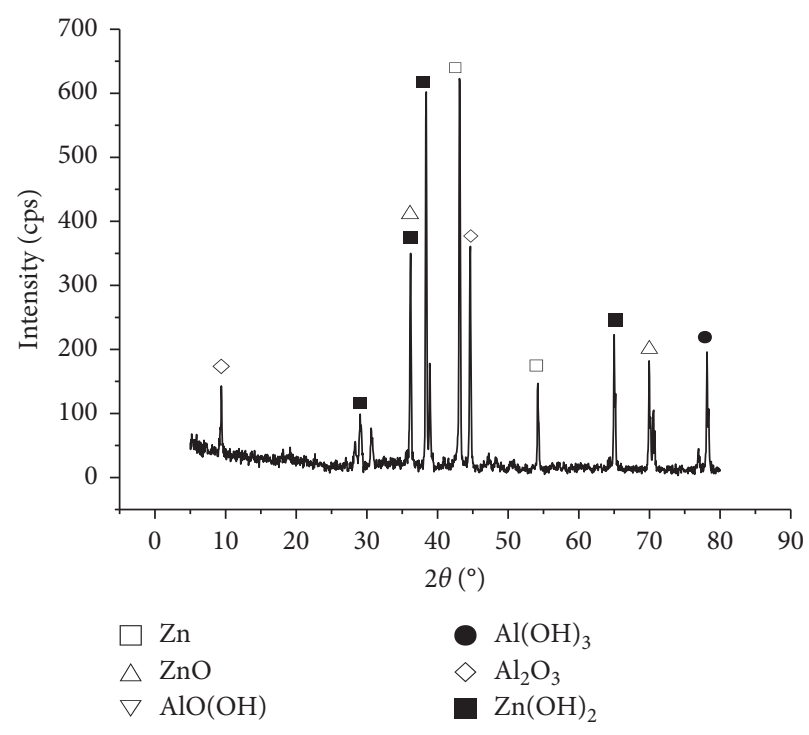

(a)

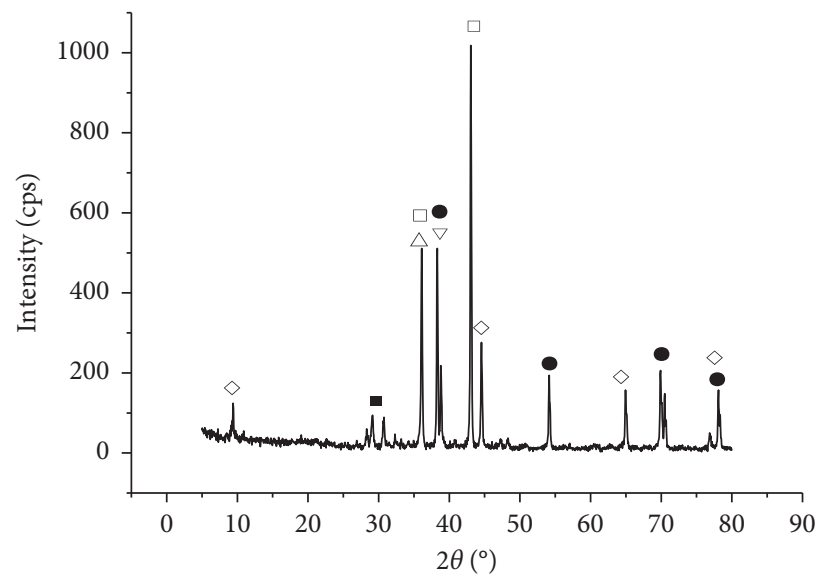

$\square \mathrm{Zn}$

$\triangle \mathrm{ZnO}$

$\nabla \mathrm{AlO}(\mathrm{OH})$
- $\mathrm{Al}(\mathrm{OH})_{3}$

$\diamond \mathrm{Al}$

- $\mathrm{Zn}(\mathrm{OH})_{2}$

(b)

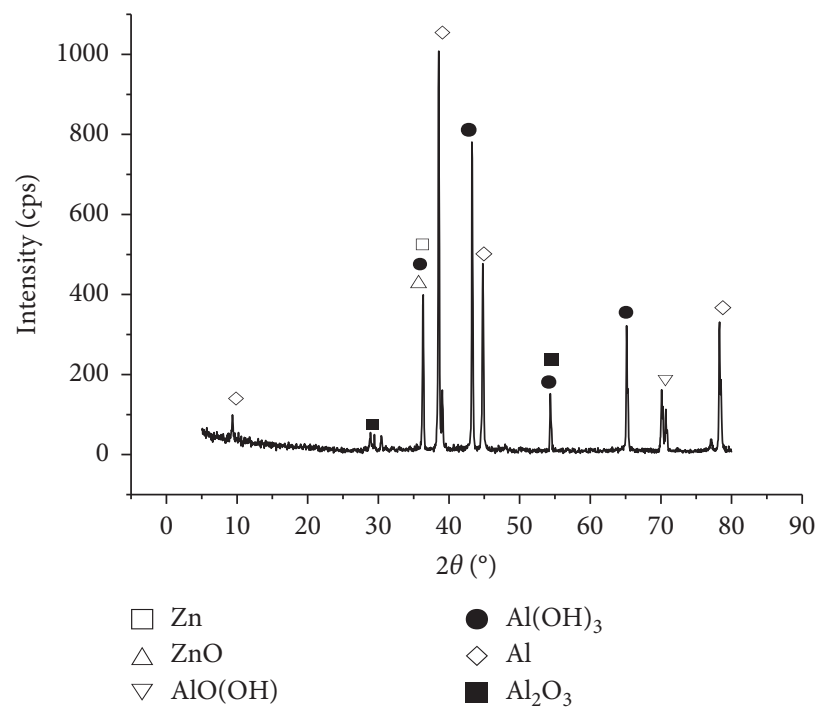

(c)

FIGURE 11: XRD diagrams of three coatings after corrosion: (a) 20\% Al-80\% Zn, (b) $30 \% \mathrm{Al}-70 \% \mathrm{Zn}$, and (c) $40 \% \mathrm{Al}-60 \% \mathrm{Zn}$. 
that a layer of white dense corrosion products was deposited on the coating surface. The surface morphology of the coating after corrosion is shown in Figure 9. It can be seen that a few holes and island particles appeared on the surface of the coatings. The distribution of corrosion products is uneven, and there are obvious corrosion pits and agglomeration of corrosion products around the corrosion pits. The corrosion products of coating $40 \% \mathrm{Al}-60 \% \mathrm{Zn}$ are relatively dense, and most of the corrosion products are flocculent. The density of corrosion products on the coating surface increased with the increase of the $\mathrm{Al}$ content. When the content of $\mathrm{Al}$ is relatively low, $\mathrm{Zn}$ is relatively active and is first corroded, forming a cathodic protection effect on $\mathrm{Al}$. From the overall corrosion morphology, with the increase of the $\mathrm{Al}$ content, the density of corrosion products on the coating surface increased. The denser the corrosion product, the more it can prevent the coating being corroded.

The samples were weighed before and after corrosion, and the average annual corrosion rate was calculated according to the corrosion weight loss of the measured samples. The calculation formula is as follows:

$$
V_{\mathrm{a}}=C \times \frac{W_{0}-W}{\rho A t},
$$

where $V_{\mathrm{a}}$ is the annual corrosion rate; $C$ is the conversion factor, and its value is $8.76 \times 10^{4} ; W_{0}$ is the quality of samples before corrosion; $W$ is the quality of the sample after corrosion; $A$ is the surface area of the sample; $\rho$ is the density of the coating surface; and $t$ is corrosion time.

According to equation (1), the corrosion rate of each coating is shown in Figure 10. The annual corrosion rate of the coating is $20 \% \mathrm{Al}-\mathrm{Zn}, 30 \% \mathrm{Al}-\mathrm{Zn}$, and $40 \% \mathrm{Al}-60 \% \mathrm{Zn}$ from large to small.

Figure 11 shows the XRD composition of three coatings after corrosion. From the diagram, the three coatings contain $\mathrm{AlO}(\mathrm{OH}), \mathrm{Al}(\mathrm{OH})_{3}, \mathrm{ZnO}$, and $\mathrm{Al}_{2} \mathrm{O}_{3}$. Passivation film is easily formed by oxidation of aluminum in aqueous solution. The anode first undergoes the anodic dissolution reaction of aluminum. With the corrosion reaction proceeding, the passive film on the coating surface is destroyed, and the corrosion reaction of the coating is intensified. In the subsequent corrosion process, because zinc is more active than the oxide film of aluminum, it can protect the oxide film of aluminum. With the continuous dissolution of zinc and the formation of $\mathrm{ZnO} \cdot \mathrm{H}_{2} \mathrm{O}$ with the $\mathrm{OH}^{-}$generated from the cathode, the product will cover the coating surface. These corrosion products can play a role of "self-sealing" plugging the pores, to some extent, blocking the penetration and diffusion of the medium into the coating [18].

The polarization curves of three coatings in $3.5 \% \mathrm{NaCl}$ solution are shown in Figure 12. The corresponding polarization curve fitting results are also listed in Table 3. There is no obvious passivation zone in the polarization process of the three coatings. The corrosion potential of the three coatings is lower than that of the substrate. The corrosion rate of the three coatings in $3.5 \% \mathrm{NaCl}$ solution is lower than that of the substrate. With the increase of the content of $\mathrm{Al}$

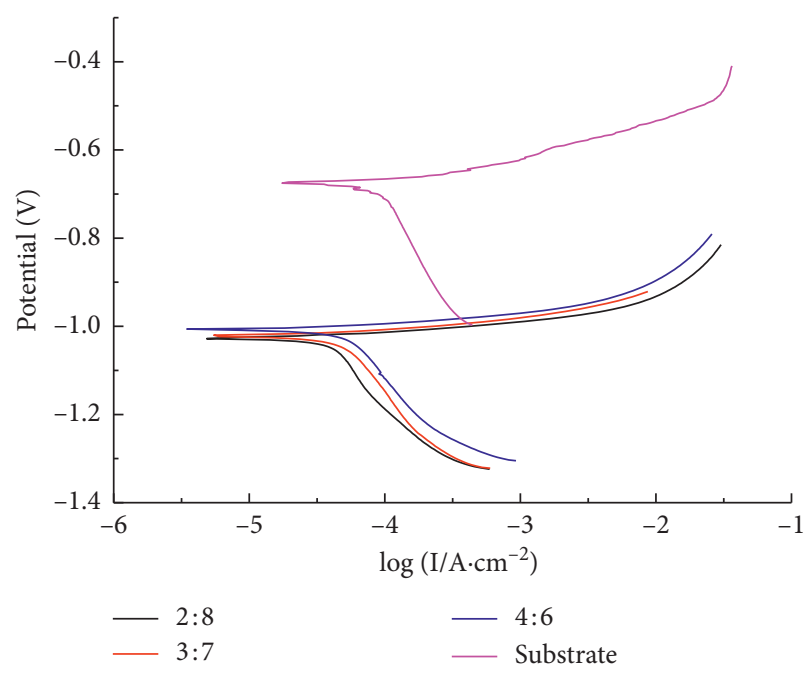

Figure 12: Polarization curves of three coatings in $3.5 \% \mathrm{NaCl}$ solution.

TABLE 3: Fitting results of several polarization parameters.

\begin{tabular}{lcc}
\hline Sample & $\mathrm{I}_{\text {corr }}(\mu \mathrm{A})$ & $\mathrm{E}_{\text {corr }}(\mathrm{V})$ \\
\hline $20 \% \mathrm{Al}-\mathrm{Zn}$ & 52.40 & -1.026 \\
$30 \% \mathrm{Al}-\mathrm{Zn}$ & 47.80 & -1.022 \\
$40 \% \mathrm{Al}-\mathrm{Zn}$ & 42.10 & -1.010 \\
Substrate & 63.70 & -0.675 \\
\hline
\end{tabular}

powder in the metal powder, the corrosion potential of the coating increases, and the corrosion rate of the coating decreases which is more conducive to the protection of the substrate.

\section{Conclusion}

(1) Three kinds of coatings were prepared by cold spraying technology, and no obvious defects were observed in the coatings. With the increase of the relative content of $\mathrm{Al}$ powder particles, the roughness of the coating decreased, porosity of the coating surface decreased from $1.52 \%$ to $0.62 \%$, and the coating became more compact. The denser the coating is, the more effective it is to protect the S135 drill pipe joint material from corrosion.

(2) From the substrate to the coating surface, the hardness value decreases gradually. The hardness of coating increases with the increase of the content of zinc powder particles. The bonding mechanism between the powder particles and the substrate of the three coatings is mainly mechanical occlusion. With the increase of the metal Al powder content, coating bonding strength increased.

(3) The potential of the three coatings is negative compared with the substrate. With the increase of the content of $\mathrm{Al}$ powder in the metal powder, the corrosion potential of the coating increased from $-1.026 \mathrm{~V}$ to $-1.01 \mathrm{~V}$. The corrosion rate of the three coatings is lower than that of the substrate. In 
immersion corrosion experiments, the distribution of corrosion products is uneven, and there are obvious corrosion pits and agglomeration of corrosion products around the corrosion pits. With the increase of the $\mathrm{Al}$ content, the density of corrosion products on the coating surface increased. Three coatings can provide effective corrosion protection for the substrate.

\section{Data Availability}

The data used to support the findings of this study are available from the corresponding author upon request.

\section{Conflicts of Interest}

The authors declare that they have no conflicts of interest.

\section{Acknowledgments}

The authors would like to acknowledge the funding support by the Chinese National Natural Science Foundation (grant no. 51974271) and the Open Fund of State Key Laboratory of Oil and Gas Reservoir Geology and Exploitation (Southwest Petroleum University) (grant no. PLN1520).

\section{References}

[1] F.-p Li, L.-h Han, Y.-g Liu, and Y. Wang, "Investigation on toughness index of high grade steel drill pipe," Journal of China University of Petroleum (Edition of Natural Science), vol. 35, no. 5, pp. 130-133, 2011.

[2] J. Li and J. Zhu, "Study on fracture characteristics of S135 steel for drill pipes," Foundry Technology, vol. 36, no. 10, pp. 2477-2478, 2015.

[3] K. A. Macdonald and J. V. Bjune, "Failure analysis of drill strings," Engineering Failure Analysis, vol. 14, no. 8, pp. 1641-1666, 2007.

[4] S. Moradi and K. Ranjbar, "Experimental and computational failure analysis of drillstrings," Engineering Failure Analysis, vol. 16, no. 3, pp. 923-933, 2009.

[5] R. M. H. Pombo Rodriguez, R. S. C. Paredes, S. H. Wido, A. Calixto, and H. Schereiner, "Comparison of aluminum coatings deposited by flame spray and by electric arc spray," Surface and Coatings Technology, vol. 202, no. 1, pp. 172-179, 2007.

[6] L. Fan, F. Tang, G. Chen, S. T. Reis, and M. L. Koenigstein, "Corrosion resistances of steel pipe coated with two types of enamel by two coating processes," Journal of Materials Engineering and Performance, vol. 27, no. 10, pp. 5341-5349, 2018.

[7] R. Nikbakht, S. H. Seyedein, S. Kheirandish, H. Assadi, and B. Jodoin, "The role of deposition sequence in cold spraying of dissimilar materials," Surface and Coatings Technology, vol. 367, pp. 75-85, 2019.

[8] L. Fan, F. Tang, S. T. Reis, G. Chen, and M. L. Koenigstein, "Corrosion resistances of steel pipes internally coated with enamel," Corrosion, vol. 73, no. 11, pp. 1335-1345, 2017.

[9] L. Fan, S. Reis, G. Chen, and M. Koenigstein, "Corrosion resistance of pipeline steel with damaged enamel coating and cathodic protection," Coatings, vol. 8, no. 5, p. 185, 2018.

[10] China National Defense Science and Technology Information Center, World Weapons and Equipment and Military
Technology Annual Development Report 2014, China National Defense Science and Technology Information Center, Beijing, China, 2015.

[11] G.-f. Zhao, Y.-y. Wang, H.-1. Zhang, J.-l. Tang, and Y.-d. Cheny, "Application of cold spraying equipment and cold spraying technology," Surface Technology, vol. 46, no. 11, pp. 198-205, 2017.

[12] H. Assadi, H. Kreye, F. Gärtner, and T. Klassen, "Cold spraying-a materials perspective," Acta Materialia, vol. 116, pp. 382-407, 2016.

[13] D. Persson, D. Thierry, and N. LeBozec, "Corrosion product formation on $\mathrm{Zn} 55 \mathrm{Al}$ coated steel upon exposure in a marine atmosphere," Corrosion Science, vol. 53, no. 2, pp. 720-726, 2011.

[14] C. Walde, D. Cote, V. Champagne, and R. Sisson, "Characterizing the effect of thermal processing on feedstock $\mathrm{Al}$ alloy powder for additive manufacturing applications," Journal of Materials Engineering and Performance, vol. 28, no. 2, pp. 601-610, 2019.

[15] S. Ngai, T. Ngai, F. Vogel, W. Story, G. B. Thompson, and L. N. Brewer, "Saltwater corrosion behavior of cold sprayed AA7075 aluminum alloy coatings," Corrosion Science, vol. 130, pp. 231-240, 2018.

[16] P. Nautiyal, C. Zhang, V. Champagne, B. Boesl, and A. Agarwal, "In-situ creep deformation of cold-sprayed aluminum splats at elevated temperatures," Surface and Coatings Technology, vol. 372, pp. 353-360, 2019.

[17] Z.-c. Shi, X.-y. Zhang, H. Chen et al., "Properties of cold spray $\mathrm{Al} / \mathrm{Zn}$ coatings on high-strength steel," Journal of Materials Engineering, vol. 43, no. 2, pp. 14-19, 2015.

[18] C. Xie, H. Li, X. Zhou, and C. Sun, "Corrosion behavior of cold sprayed pure zinc coating on magnesium," Surface and Coatings Technology, vol. 374, pp. 797-806, 2019.

[19] C. J. Huang, K. Yang, N. Li et al., "Microstructures and wearcorrosion performance of vacuum plasma sprayed and cold gas dynamic sprayed Muntz alloy coatings," Surface and Coatings Technology, vol. 371, pp. 172-184, 2019.

[20] W.-Y. Li, H. Liao, C.-J. Li, G. Li, C. Coddet, and X. Wang, "On high velocity impact of micro-sized metallic particles in cold spraying," Applied Surface Science, vol. 253, no. 5, pp. 28522862, 2006.

[21] F. Raletz, M. Vardelle, and G. Ezo'o, "Critical particle velocity under cold spray conditions," Surface and Coatings Technology, vol. 201, no. 5, pp. 1942-1947, 2006.

[22] D. Lv, Z. Lian, and T. Zhang, "Study of cavitation and cavitation erosion quantitative method based on image processing technique," Advances in Civil Engineering, vol. 2018, Article ID 5317578, 10 pages, 2018.

[23] A. G. Jo and C. C. Berndt, "Effects of standoff distance on porosity,phase distribution and mechanical properties of plasma sprayed Nd-Fe-B coatings," Surface and Coatings Technology, vol. 216, pp. 127-138, 2013.

[24] G. A. Baglyuk, S. G. Pyatachuk, and A. A. Mamonova, "The structure and properties of boride coatings depending on the porosity of powder steel preforms," Powder Metallurgy and Metal Ceramics, vol. 53, no. 7-8, pp. 417-422, 2014. 